\title{
Expressão da atitude através da prosódia em indivíduos com doença de Parkinson idiopática
}

\author{
Luciana Lemos de Azevedo ${ }^{1}$
}

Azevedo, LL. Expressão da atitude através da prosódia em indivíduos com doença de Parkinson idiopática [tese de doutorado]. Belo Horizonte: Faculdade de Letras da Universidade Federal de Minas Gerais; 2007.

Pacientes com doença de Parkinson (DP) apresentam incidência significativa de alterações de voz e fala. O presente estudo teve como objetivo verificar os parâmetros prosódicos empregados na expressão das atitudes em indivíduos com DP idiopática (DPI), além de estudar a interferência da levodopa e do método Lee Silverman de Tratamento Vocal® adaptado, e comparar com o padrão normalmente empregado por informantes que não apresentavam a referida doença. Para tanto, foram selecionados 10 informantes idosos com DPI e 10 informantes idosos sem alterações neurológicas. Todos os informantes foram submetidos à gravação do corpus em ambiente acusticamente tratado, onde eram solicitados a emitir três enunciados inseridos em um contexto, sendo que tais enunciados foram produzidos em quatro momentos: expressando a atitude de certeza (AC), expressando a atitude de dúvida (AD), expressando a modalidade declarativa (MD) e expressando a modalidade interrogativa (MI).

A partir da análise crítica dos dados, pudemos observar que, na comparação entre a MD e a AC e entre a MI e a AD, apenas o grupo controle (GC) apresentou um diferencial na expressão da AC, que foi o aumento da amplitude de variação melódica da átona pretônica. Ao realizarmos uma análise mais detalhada, levando em consideração cada um dos 10 informantes do GC, pudemos verificar que todos eles apresentaram de uma a três variáveis que diferenciavam tanto a MD da AC quanto a MI da $\mathrm{AD}$, o que evidencia que a manipulação dos parâmetros prosódicos para expressar as atitudes é uma característica individual. Já para os informantes com DP não foi observado nenhum comportamento prosódico que caracterizasse a expressão das atitudes (ao compararmos a MD com a AC e a MI com a AD). No entanto, quando comparamos todas as atitudes (certeza e dúvida) com todas as modalidades (declarativa e interrogativa), observamos que a duração do enunciado foi uma variável de peso na expressão das atitudes, apresentando-se aumentada para a expressão delas, o que não aconteceu apenas para informantes parkinsonianos sem nenhum tipo de tratamento.

Ao estudar o emprego dos parâmetros prosódicos por parte destes informantes sem levar em consideração as atitudes, observamos que a DP prejudica a produção eficiente dos parâmetros prosódicos. Após a administração da levodopa, observamos uma melhora significativa nos parâmetros de duração, mas mesmo assim os parkinsonianos não chegam a ter um desempenho tão satisfatório quanto o do GC. O tratamento medicamentoso promoveu melhora nos parâmetros de duração e o tratamento fonoaudiológico e a associação dos tratamentos (fonoaudiológico e medicamentoso) promoveram a melhora de todos os parâmetros prosódicos: frequência fundamental, duração e intensidade.

Foi possível observar um padrão melódico semelhante na emissão dos enunciados, sendo que, para todos os grupos de comparação, foi verificado que enunciados de MD e AC apresentaram pico de frequência fundamental na átona pretônica (exceto para a expressão da AC para informantes do sexo feminino do GC, cujo pico foi na tônica nuclear), enquanto enunciados de MI e AD apresentaram o pico de frequência fundamental na tônica nuclear.

Trabalho apresentado ao Programa de Pós-Graduação em Estudos Linguísticos da Faculdade de Letras da Universidade Federal de Minas Gerais - UFMG - Belo Horizonte (MG), Brasil, para obtenção do título de doutor em Linguística, sob orientação do Prof. Dr. César Augusto da Conceição Reis e Prof. Dr. Francisco Eduardo Costa Cardoso.

(1) Doutora, Professora Adjunto do Curso de Fonoaudiologia e Educação Física da Pontifícia Universidade Católica de Minas Gerais - PUC-Minas Belo Horizonte (MG), Brasil.

Endereço para correspondência: Luciana Lemos de Azevedo. R. Pitangueiras, 331/401, Bairro Santo Antônio, Belo Horizonte - MG, CEP: 30350-200.

E-mail: azevedoll@terra.com.br 
